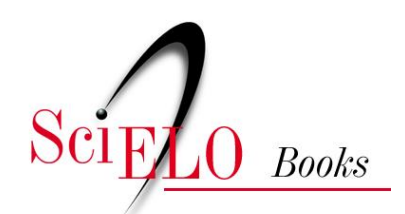

\title{
Experiencias de buenas prácticas \\ 2. Aplicaciones informáticas para el aprendizaje de inglés en universitarios con discapacidad visual
}

\author{
Cristian Castañeda \\ Miriam Gallegos
}

\section{SciELO Books / SciELO Livros / SciELO Libros}

CASTAÑEDA, C., and GALLEGOS, M. Aplicaciones informáticas para el aprendizaje de inglés en universitarios con discapacidad visual. In: GALLEGOS NAVAS, M., ed. La inclusión de las TIC en la educación de personas con discapacidad: relatos de experiencias [online]. Quito: Editorial AbyaYala, 2019, pp. 53-56. ISBN: 978-9978-10-495-8. https://doi.org/10.7476/9789978104958.0005.

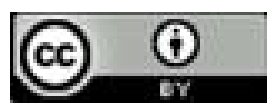

All the contents of this work, except where otherwise noted, is licensed under a Creative Commons Attribution 4.0 $\underline{\text { International license. }}$

Todo o conteúdo deste trabalho, exceto quando houver ressalva, é publicado sob a licença Creative Commons Atribição 4.0.

Todo el contenido de esta obra, excepto donde se indique lo contrario, está bajo licencia de la licencia $\underline{\text { Creative }}$ Commons Reconocimento 4.0. 
como también adquieran un adecuando desenvolvimiento en actividades de la vida diaria, en actividades escolares esta función permite manejarse adecuadamente en el aula de clase ya que sentado en el pupitre, puede magnificar o ampliar la pizarra y en el caso de bajar la vista al escritorio, el dispositivo cambia automáticamente el enfoque para facilitar la lecto-escritura.

Los estudiantes con baja visión acogieron con mucho entusiasmo el uso de estos apoyos en el aula, se evidenció la colaboración de los docentes para evitar que los equipos sufran daños ya que los estudiantes sentían curiosidad de los mismos. De igual manera las familias están muy contentas con la yuda recibida ya que el rendimiento escolar de sus hijos está al nivel de sus compañeros.

\section{Aplicaciones informáticas para el aprendizaje de inglés en universitarios con discapacidad visual}

"Dime y lo olvido, enséñame y lo recuerdo, involúcrame y lo aprendo" (Benjamín Franklin)

Universidad Politécnica Salesiana

Ecuador

Quito

Responsable: Cristian Castañeda

Gestores de la práctica: Tiflobiblioteca UPS

Esta experiencia presenta estrategias metodológicas para el aprendizaje de una segunda lengua de los estudiantes con discapacidad, con cinco estudiantes con discapacidad visual que cursan diversas carreras en la Universidad Politécnica Salesiana del Ecuador, sede Quito

\section{Motivación}

Para el aprendizaje de una segunda lengua de los estudiantes con discapacidad en la universidad, requieren que los docentes utilicen diferentes estrategias metodológicas en sus clases, para cubrir las expec- 
tativas de aprendizaje en las competencias de hablar, escuchar, escribir y leer en otro idioma, de estas cuatro competencias el hablar y escuchar son fácilmente asimiladas por los estudiantes con discapacidad, por lo que es importante que los docentes puedan realizar ajustes razonables para que a través de nuevas estrategias metodológicas y recursos accesibles se pueda desarrollar las capacidades de escribir y leer, los docentes manifiestan el desconocimiento de las estrategias, así como, la carencia de recursos didácticos ajustados a las necesidades de los estudiantes como: cartillas en sistema braille, vocabulario en audio, expresiones idiomáticas, textos de lectura, material de trabajo en clase, digitalización de textos accesibles en formato Word, pdf y txt, situaciones que se convierten en barreras que limitan las posibilidades de aprendizaje de la lectura y escritura en un contexto de equidad.

La metodología de trabajo que sustenta esta práctica de aprendizaje, es la utilización de herramientas tiflotécnicas ${ }^{14}$ fundamentales utilizadas por estudiantes con discapacidad visual en su vida diaria como: el lector de pantalla Jaws en su versión 17, el convertidor de texto en audio Balabolka ${ }^{15}$ y la herramienta propia del paquete de Office Microsoft Word.

Para la ejecución de la práctica se contó con la participación de docentes del Instituto de Idiomas de la Institución, personas encargadas de la tiflobiblioteca de la UPS, estudiantes de la carrera de Pedagogía, docentes del Grupo de Apoyo a la Inclusión, los tutores participantes en la adaptación de material accesible y los estudiantes con discapacidad visual de la misma Institución.

\section{Objetivo}

Fortalecer el proceso pedagógico de enseñanza del idioma inglés para estudiantes con discapacidad visual, tilizando la tecnología como recurso de apoyo incrementando recursos bibliográficos y opciones de

14 https://goo.gl/vGY2YR

15 https://goo.gl/JgkE8c 


\section{5}

accesibilidad, que faciliten el desempeño académico y la autonomía de los estudiantes.

\section{Desarrollo de la experiencia}

En primer lugar se observó e investigó las necesidades de aprendizaje en la materia de inglés que manifestaban los estudiantes con discapacidad visual. Los resultados de esta investigación permitieron evidenciar la necesidad de proveer recursos didácticos accesibles que mejoren la comprensión y el aprendizaje de la segunda lengua.

En segundo lugar, se realizaron entrevistas con los docentes para conocer, cuál es su criterio y requerimientos con relación a la enseñanza de inglés a estudiantes con discapacidad visual, la información de los docentes estuvo centrada en los temores sobre la falta de herramientas metodológicas y material didáctico empleado en el proceso de formación, lo que limita la participación integral del estudiante, y solicitan además se provea de capacitación en proyectos de formación incluyente.

Actualización constante del inventario de material base y de apoyo disponible para estudiantes con discapacidad visual.

Adaptación del material bibliográfico de aprendizaje del idioma inglés de los Textos de Cambridge ("Interchange") en formato PDF, describiendo gráficos, tablas y cuadros para facilitar la lectura y aprendizaje con las aplicaciones de Word, Jaws ${ }^{16}$ y Balabolka a personas con discapacidad visual.

Validación y puesta en práctica del material adaptado usando el lector de pantalla jaws, convertidor de texto en audio Balabolka.

Capacitación a los docentes en el manejo del material y la forma de trabajo con los estudiantes del Instituto de Idiomas.

16 https://goo.gl/DrZLrb 


\section{6}

Encuesta de impacto y sugerencias frente al proceso de apoyo a los estudiantes con discapacidad visual.

Aplicación estudiantil de la escritura del idioma inglés con los conocimientos impartidos por los docentes.

\section{Recursos utilizados}

\section{Figura 14}

Recursos y materiales con adaptación
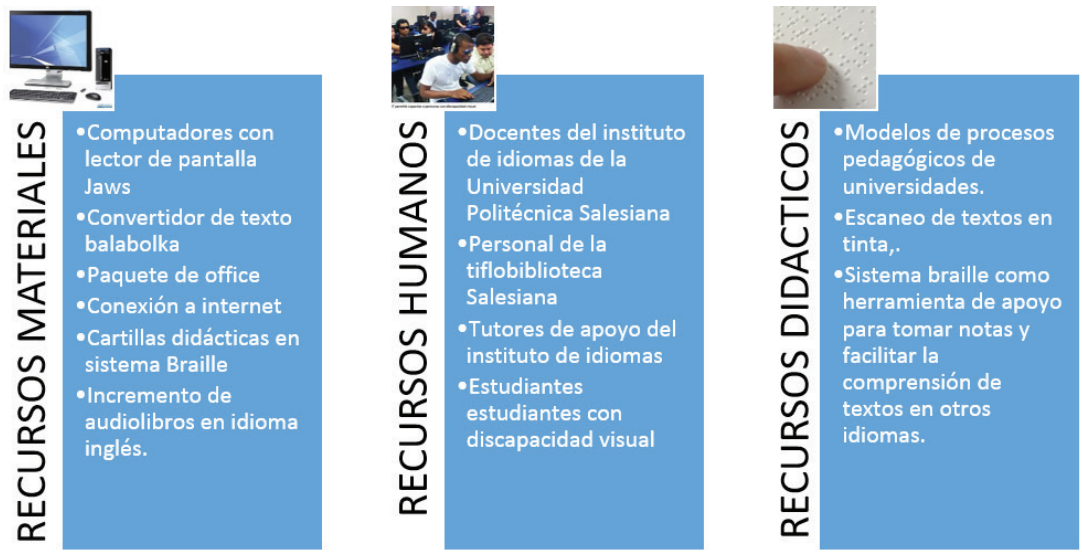

Fuente: Miriam Gallegos (2016)

\section{Logros obtenidos}

Los estudiantes con discapacidad visual:

- Han aprobado los exámenes de inglés para realizar estudios de posgrado.

- Conocen el manejo de páginas y herramientas web en idioma inglés.

- Lectura y escritura académica de textos en idioma inglés. 